\title{
Treatment strategies for carotid artery penetrating injury: a case report and literature review
}

\author{
Nannan Gao ${ }^{1,2}$, Yan Zhao ${ }^{1}$, Litong Zhang ${ }^{1}$, Wei Wu ${ }^{3}$, Jianning Zhang ${ }^{1}$ and Xinyu Yang ${ }^{\text {** }}$
}

\begin{abstract}
Background: The carotid artery is an important blood vessel in the human body. Its ruptures caused by accidents can be lethal cases without timely treatment. Currently, successful rescue cases have rarely been reported, hence we present the following case.

Case presentation: A patient who was a 46-year-old male admitted due to left neck trauma that lasted almost a day. The CT angiography (CTA) of the neck showed two pseudoaneurysms: one on the anterior wall and one on the posterior wall of the carotid artery. In our case, we considered an open approach to reconstruct the carotid artery. After excision of the aneurysm, the internal carotid artery was stitched. Electrophysiological monitoring and shunt were used during the operation. The postoperative course was uneventful, and the patient remains free of symptoms.
\end{abstract}

Conclusions: Many departments jointly and positive and effective surgical intervention are the key to reduce morbidity and mortality of carotid artery penetrating injury.

Keywords: Carotid artery, Penetrating injury, Pseudoaneurysm, Electroencephalography

\section{Background}

The carotid artery is an important blood vessel in the human body. Due to its high blood flow, ruptures caused by accidents such as stab wounds, gunshot wounds, car accident injuries can cause rapid and massive blood loss in a short period, which can be lethal cases without timely treatment. To date, successful rescue cases have rarely been reported, hence we present the following discussion based on this case and a literature review.

\section{Case presentation}

The patient who was a 46-year-old male admitted due to left neck trauma that lasted almost a day. The left side of the patient's neck was penetrated by a foreign metal objectprior to admission. The wound immediately showed projectile bleeding, and the patient applied pressure on the bleeding site himself. A radiograph of the neck revealed a "foreign metal object in the soft tissue of the left upper neck (Fig. 1b)

\footnotetext{
* Correspondence: yangxinyu@tijmu.edu.cn

1 Department of Neurosurgery, Tianjin Medical University General Hospital,

Tianjin 300052, People's Republic of China

Full list of author information is available at the end of the article
}

and the foreign object's size is about $1.5 \mathrm{~cm}$ (Fig. 1a)." A computed tomography (CT) scan of the neck showed the shadow of flaky foreign objects with metal density at the carotid sheath space on the left side of the neck next to the parapharyngeal space. After the patient was stabilized, CT angiography (CTA) of the neck showed two cystic bumps anterior and posterior to the starting point of the left internal carotid artery that were diagnosed as multiple traumatic pseudoaneurysms (Fig. 2a). On the day of the surgery, digital subtraction angiography (DSA) of the neck was performed in a hybrid operating room, followed by surgical exploration to separate the common carotid artery at the proximal end of the pseudoaneurysm with the internal and external carotid artery at the distal end of the pseudoaneurysm, and a carotid artery shunt was applied and the external carotid artery was blocked. The pseudoaneurysm was then resected and the foreign object was removed and the artery is spasmadic (Fig. 3b). Breakages of both anterior and posterior walls of the carotid artery were stitched (Fig. 4c, d). Electrophysiological monitoring and other monitoring devices were used during the operation. The patient recovered uneventfully after the operation. No pseudoaneurysm was detected upon 


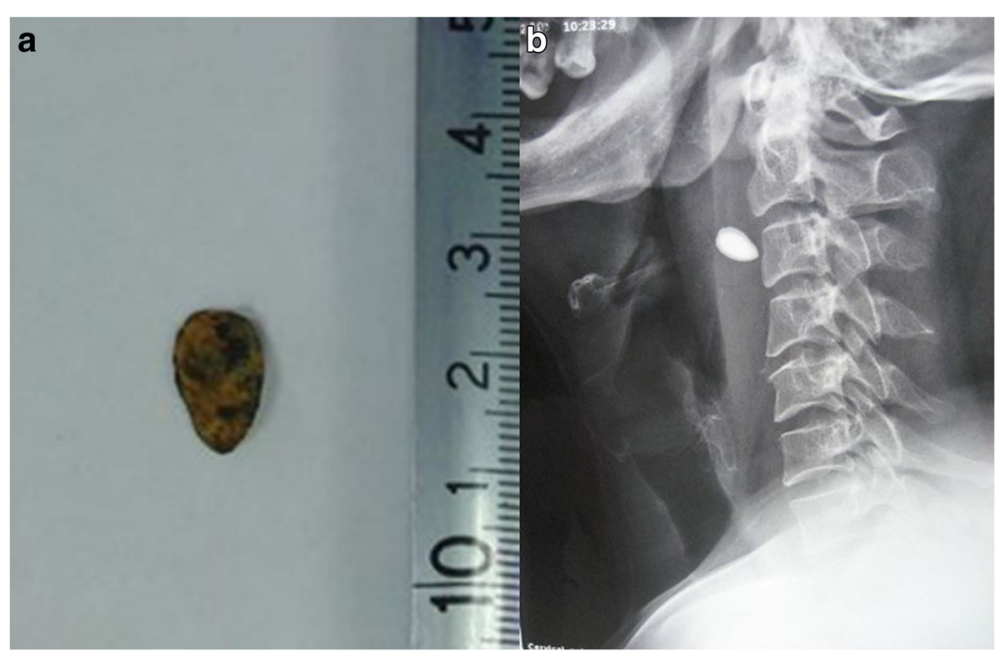

Fig. 1 The patient's neck radiogragh: a foreign metal object is in the soft tissue of the left upper neck (b) and the foreign object's size is about $1.5 \mathrm{~cm}(\mathbf{a})$

reexamination of the carotid artery 3 months after operation (Fig. 2b), and the follow-up was made in 3 years, and the carotid ultrasound doppler shows no relapse occurred and common carotid artery (Fig. 5a), external carotid artery (Fig. 5b) and internal carotid artery (Fig. 5c) keep vsssels open. The patient did not suffer from any sequelae.

\section{Discussion and conclusions}

On-site first aid

Major carotid artery injury leads to a large amount of "spring-like" or projectile bleeding with obvious swelling in the neck; applying rapid tamponade and local pressure for hemostasis are crucial in on-site first aid. Major

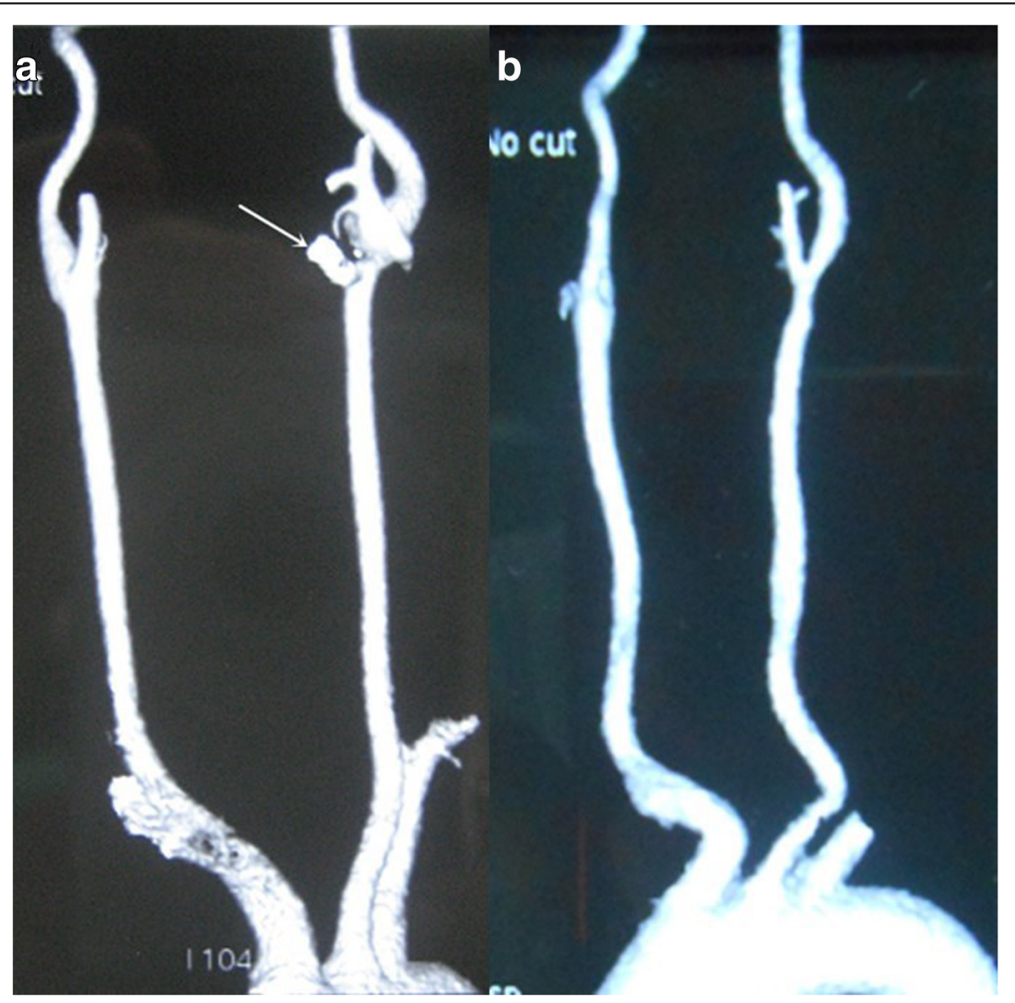

Fig. 2 The patient's preoperative and postoperative CTA images: the Preoperative CTA shows the pseudoaneurysm (a) and no pseudoaneurysm was detected upon reexamination of the carotid artery 3 months after operation (b) 


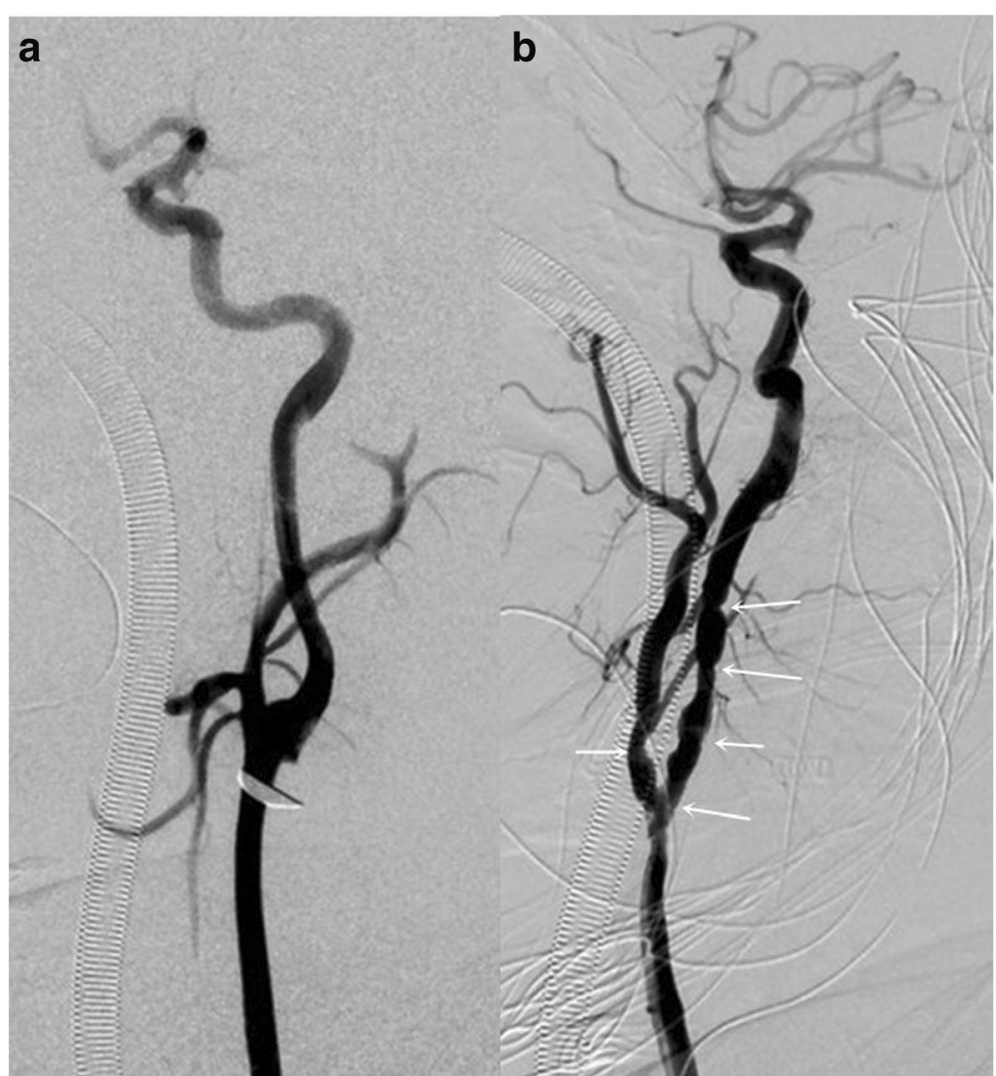

Fig. 3 The patient's preoperative and immediately postoperative DSA images: the carotid artery is penetrated by a foreign metal object (a) and the pseudoaneurysm was then resected and the foreign object was removed and the artery is spasmadic (b)

carotid arteries have large diameters and are under high pressure, and injury can cause hemorrhagic shock within a short period. Internal carotid vein injury can also cause air embolism, both of which will lead to death or severe complications. The application of direct pressure to the common carotid artery can reduce bleeding; however, this is difficult to perform and the duration cannot be long or it will lead to cardiopulmonary arrest and cerebral ischemia. Surgical dressing for hemostasis is not suitable for the neck due to its special anatomical structure and loose tissues. Additionally, loose dressings cannot stop the bleeding, whereas tight dressings compress the trachea and cause breathing difficulties. Tamponade combined with local pressure for hemostasis can effectively reduce the amount of blood loss and prevent air embolism caused by phleborrhexis. This is simple to perform with few complications. However, in clinical first aid, there is an extremely contradictory relationship between pressure hemostasis and brain ischemia; thus, it is a confusing problem in clinical first aid. In this case, using local pressure, the patient's carotid bleeding was stopped without shock or brain ischemic symptoms caused by blood loss or ischemia.

\section{Pseudoaneurysm treatment}

Pseudoaneurysm is a complication of blood vessel injury in which rupture of the entire arterial wall and hemorrhage are caused by a gunshot wound, stab wound, or iatrogenic injury. Pseudoaneurysms might cause local nerve dysfunction, local compression, and bleeding. Treatment of pseudoaneurysms includes observation (with or without the application of anticoagulation), intervention, and surgical repair [1]. The choice of treatment depends on the patient's condition and the pseudoaneurysm size. Patients with larger pseudoaneurysms or with symptoms (stroke, hemorrhage, or compression) should undergo surgical intervention. Treatment of small pseudoaneurysms with no symptoms remains controversial [2]. Data about naturally formed pseudoaneurysms are still lacking. We found that of the iatrogenic femoral artery pseudoaneurysms reported in the literature, nearly $40 \%$ of pseudoaneurysms caused embolisms with no sequelae. In addition, small pseudoaneurysms (diameter $<1.8 \mathrm{~cm}$ ) tend to self-heal, whereas larger ones tend to worsen. It is impossible for all femoral artery pseudoaneurysms to form embolisms; at least one third of the patients require surgical treatment. Blunt injury to the carotid artery is usually found in the extracranial 


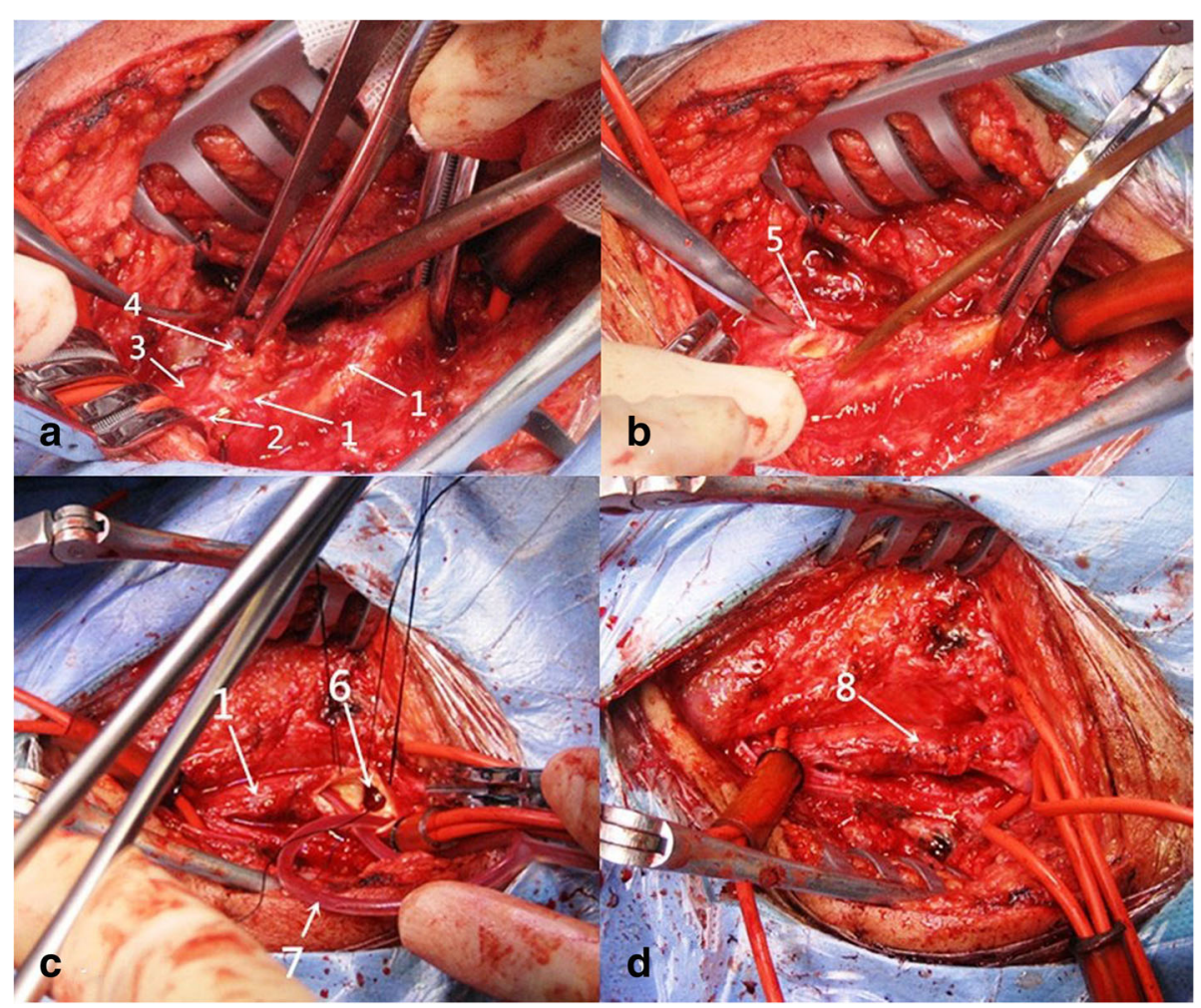

Fig. 4 The separation and stitching process of carotid artery: the carotid artery is separated: 1, common carotid artery; 2, external carotid artery; 3, internal carotid artery; 4, pseudoaneurysm; (a, $\mathbf{b})$ and the carotid artery shunt and breakages of both anterior (5) and posterior (6) walls of the carotid artery were stitched $(\mathbf{c}, \mathbf{d})$

portion of the internal carotid artery near the basis cranii. Intima exfoliation can cause stenosis or occlusion and might form pseudoaneurysm. Application of systemic anticoagulants (heparin, warfarin, and antiplatelets) can improve prognosis [3]. In patients for whom medical treatments were ineffective, direct surgical repair can be difficult due to the difficulty of distal end exposure, hence intervention using stenting and coil embolization treatment has been shown to be superior and achieve good results [4-6]. Patients with pseudoaneurysms caused by sharp injury to the carotid artery are usually unstable and sometimes demonstrate obvious symptoms of impeded respiratory tract, continuous enlargement of hematomas, and significant bleeding that require immediate surgical exploration. To prevent long-term complications, pseudoaneurysm resection is necessary [7].

\section{Anti-infection}

As the environment and foreign objects caused severe contamination to the wound when the patient was injured, and the patient had missed the opportunity to clean and stitch the wound within $8 \mathrm{~h}$ after the injury,
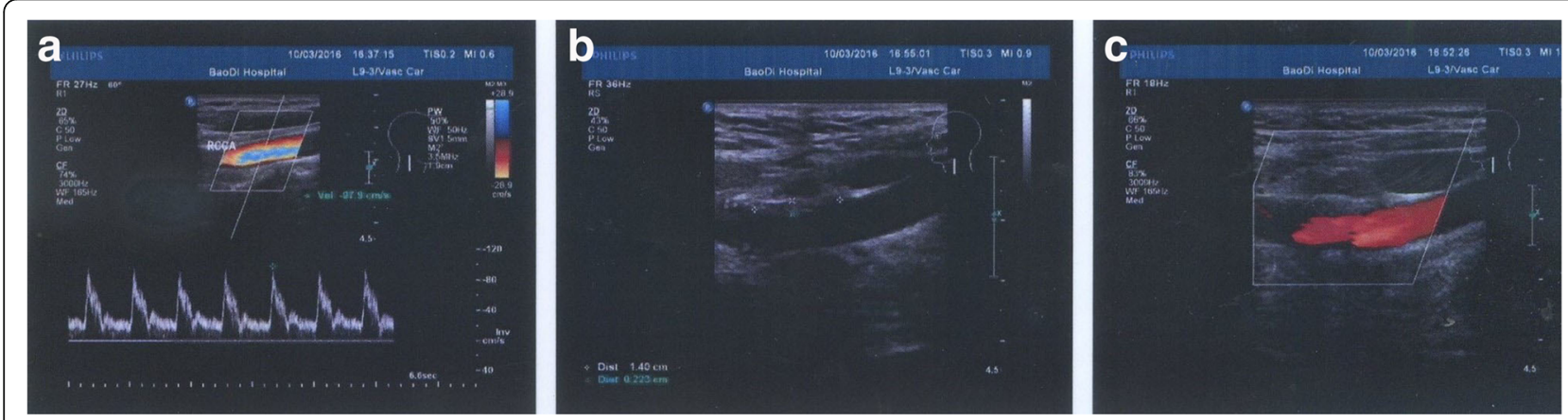

Fig. 5 The follow-up was made in 3 years, and the carotid ultrasound doppler shows no relapse occurred and common carotid artery (a), external carotid artery (b) and internal carotid artery (c) keep vsssels open 
the wound was already infected and the bacterial culture of the wound exudate showed saprophytic subspecies of saprophytic staphylococcus. Hence, the patient underwent open drainage and antibiotics to control infection. Routine drainage should be placed for $24 \mathrm{~h}$ after surgery combined with antibiotics to control the infection.

\section{Protection of brain}

Electroencephalography (EEG) monitoring and carotid artery shunt were used during surgery. EEG is extremely sensitive to reductions in cerebral blood flow; thus, it can be used to guide surgeons and anesthetists in intracranial aneurysm and other surgeries that need to block the blood-supplying arteries of the brain. EEG monitoring is routinely used during surgery to monitor blood supply conditions of the brain at any time, selectively use intraoperative shunt to eliminate intraoperative stroke, and reduce the occurrence rate of perioperative stroke to $<1 \%$ [8]. Another study showed that for patients with carotid artery stenosis with or without symptoms, employing both EEG monitoring and selective carotid artery shunt during carotid endarterectomy (CEA) result in lower stroke rates than the sole use of intracavitary shunt; therefore, selective shunt might be better than non-selective shunt [9]. Not using shunting during CEA might eliminate risks such as the shifting of plaques at the shunt location and damage to distal arterial walls while also providing a better view of distal plaques during surgery [10]. The patient in this case was relatively young, and no obvious artery atherosclerotic plaques were seen during the surgery. Two pseudoaneurysms were formed due to the injury with breakages in both the anterior and posterior walls, and the duration of surgery was long. Intraoperative EEG monitoring and shunting were employed to prevent prolonged blockage of the common carotid artery.

\section{Complications}

The neck lies in the path of many important nerves including the cervical branch of the facial nerve, hypoglossal nerve, accessory nerve, vagus nerve (recurrent laryngeal nerve), and cervical sympathetic trunk. Direct injury of the neck or pseudoaneurysm compression following carotid artery injury causes permanent or temporary dysfunction of these important nerves and structures, resulting in corresponding clinical symptoms. For example, hypoglossal nerve injury causes curving of the tongue to the affected side, unilateral recurrent laryngeal nerve injury causes hoarseness, and cervical sympathetic trunk compression causes Horner syndrome.

\section{Perioperative and anesthesia management}

Penetrating cerebral injuries caused foreign bodies are rare in civilian neurosurgical trauma, although there are various reports to blast or gunshot injuries in warfare due to multiple foreign bodies like pellet and nails $[11,12]$. The hemodynamic instability which is the most commom perioperative complication usually is mild and resolved in one or 2 days. Perioperative control of blood pressure is very important. Also, cerebral ischemia is a common complication and can be reduced by intraoperative monitoring and selective shuting and improve blood circulation drugs. The clinical evaluation and perioperative monitoring of caradiac function are mandatory to prevent myocardial infarction. On the basis of general anesthesia, local hypothermia and drug therapy and other comprehensive measures have a certain protective effect of the brain, but can not completely emimate cerebral ischemia-reperfusion injury [13]. Tacit coorperation of neurosurgeons and anesthetist is also the kye to success. In all, perioperatove and anesthesia management strategies are need for continued research in the field of the carotid artery penetrating injury.

Treatment of the carotid artery penetrating injury in this case can be summarized as follows: neck injury is an extremely urgent issue for which effective post-traumatic pressure hemostasis is the key to on-site first aid; a neck penetrating injury should not be considered a simple injury for which only simple stitching is applied; preparations should be made for complex circumstances including artery repair and treatments for combined injuries of other tissues such as injuries of the jugular vein, thyroid, and trachea; and attention should be paid to protecting brain tissues during surgery to reduce complications; and focus on perioperative management.

We report a unique case of carotid artery penetrating injury. Many departments jointly positive and effective surgical intervention are the key to reduce morbidity and mortality of carotid artery penetrating injury.

\section{Acknowledgements \\ Thank you for all partners' contribution to this paper.}

\section{Funding}

NSTC-81571144 and NSFT-15JCDJC36500 were available in support of this study.

\section{Availability of data and materials}

All data generated or analysed during this study are included in this published article..

\section{Open access}

This article is distributed under the terms of the Creative Commons Attribution 4.0 International License (http://creativecommons.org/licenses/by/ 4.0/), which permits unrestricted use, distribution, and reproduction in any medium, provided you give appropriate credit to the original author(s) and the source, provide a link to the Creative Commons license, and indicate if changes were made. The Creative Commons Public Domain Dedication waiver (http://creativecommons.org/publicdomain/zero/1.0/) applies to the data made available in this article, unless otherwise stated. 
Zhao and Nannan Gao revised the English language. All authors have accepted the final version for publication.

\section{Ethics approval and consent to participate}

The manuscript has ethics approval and consent to participate by the medical ethics committee of Tianjin Medical University General Hospital (20170035). Informed consent has been obtained and this report was processed according to the principles expressed in the Declaration of Helsinki.

\section{Consent for publication}

The patient was informed that the case would be submitted for publication and they provided consent. The consent form is available upon request.

\section{Competing interests}

The authors declare that they have no competing interests.

\section{Author details}

'Department of Neurosurgery, Tianjin Medical University General Hospital, Tianjin 300052, People's Republic of China. ${ }^{2}$ Department of Neurosurgery, TianTeda Hospital, Tianjin 300457, People's Republic of China. ${ }^{3}$ Department of Stomatology, Tianjin Medical University General Hospital, Tianjin 300052, People's Republic of China.

\section{Received: 25 December 2016 Accepted: 31 October 2017}

Published online: 06 December 2017

\section{References}

1. UI Haq T, Yaqoob J, Munir K, Usman MU. Endovascular-covered stent treatment of posttraumatic cervical carotid artery pseudoaneurysms. Australas Radiol. 2004;48:220-3.

2. Mussa FF, Towfigh S, Rowe VL, Major K, Hood DB. Current trends in the management of iatrogenic cervical carotid artery injuries. Vasc Endovasc Surg. 2006;40:354-61.

3. Cothren CC, Moore EE, Biffl WL, Ciesla DJ, Ray CE. Anticoagulation is the gold standard therapy for blunt carotid injuries to reduce stroke rate. Arch Surg. 2004;139:540-5.

4. Redekop G, Marotta T, Weill A. Treatment of traumatic aneurysms and arteriovenous fistulas of the skull base by using endovascular stents. J Neurosurg. 2001;95:412-9.

5. Scavee V, De Wispelaere JF, Mormont E, Coulier B, Triqaux JP. Pseudoaneurysm of the internal carotid artery: treatment with a covered stent. Cardiovasc Intervent Radiol. 2001;24:283-5.

6. Loffroy R, Gergele F, Rao P, Geschwind JF. Endovascular management of a posttraumatic pseudoaneurysm of the common carotid artery with superselective coil embolization. J Vasc Surg. 2011:53:1119-20.

7. Doudle MW, Raptis S. Traumatic aneurysms of the carotid arteries. Aust N Z J Surg. 1996:66:847-9.

8. Schneider JR, Droste JS, Schindler N, Golan JF, Bernstein LP. Carotid endarterectomy with routine electroencephalography and selective shunting: influence of contralateral internal carotid artery occlusion and utility in prevention of perioperative strokes. J Vasc Surg. 2002;35:1114-22.

9. Woodworth GF, McGirt MJ. Than KD, Huang J, Perler BA. Selective versus routine intraoperative shunting during carotid endarterectomy: a multivariate outcome analysis. Neurosurgery. 2007;61:1170-6.

10. Tan TW, Garcia-Toca M, Marcaccio EJ, Carney WI, Machan JT. Predictors of shunt during carotid endarterectomy with routine electroencephalography monitoring. J Vasc Surg. 2009:49:1374-8.

11. Xu M, Wen J, Zhu X, Chen P, Wang C. A rare self-injurious case of multiple penetrating brain injury by nails in a young patient with depressive disorder. Acta Neurol Belg. 2015:115:767-9.

12. Hussain M, Bari ME. Sucide bomb attack causing penetrating craniocerebral injury. Chin J Traumatol. 2013;16:51-3.

13. Eder F, Meyer F, Huth C, Halloul Z, Lippert H. Penetrating abdominothoracic injuries:report of four imprecsive, spectacular and representative cases as well as their surgical management. Pol Przegl Chir. 2011;83:117-22.

\section{Submit your next manuscript to BioMed Central and we will help you at every step:}

- We accept pre-submission inquiries

- Our selector tool helps you to find the most relevant journal

- We provide round the clock customer support

- Convenient online submission

- Thorough peer review

- Inclusion in PubMed and all major indexing services

- Maximum visibility for your research

Submit your manuscript at www.biomedcentral.com/submit
Biomed Central 